\title{
JEJAK KARBON KONSUMSI LPG DAN LISTRIK PADA AKTIVITAS RUMAH TANGGA DI KOTA DENPASAR, BALI
}

\author{
I Gusti Ngurah Made Wiratama ${ }^{1 *)}$, I Made Sudarma ${ }^{2)}$, I Made Adhika ${ }^{3)}$ \\ 1)Program Magister Ilmu Lingkungan Universitas Udayana, Denpasar \\ ${ }^{2)}$ Fakultas Pertanian Universitas Udayana, Denpasar \\ ${ }^{3}$ Fakultas Teknik Universitas Udayana, Denpasar \\ *)rahde.wiratama@gmail.com
}

\begin{abstract}
Every one of us uses carbon dioxide emitting energy source in our daily activities. The purposes of this research were to obtain information on the level of household activities of carbon footprint and to obtain information on the most influential factor of household activities in Denpasar City. The research method employed was the descriptive quantitative. The analysis of the first purpose was obtained by the multiplication of emission factor and the use of LPG and electrical capacity. The analysis of the second purpose was obtained by implementing the analysis of doubled linier regression supported by employing SPSS version 16.00 program for Windows. The research result showed that the average of the total carbon footprint was as big as 138,037.02 $\mathrm{g}$ of carbon/month. Based on that average, the total of carbon footprint in Denpasar city with as many as 15,908 households was $2,195.89$ ton $\mathrm{CO}_{2} \mathrm{e} / \mathrm{month}$. The statistic analysis test showed the factors that influenced the carbon footprint were the amount of household members, the amount of household equipments which needed LPG to operate, the amount of household equipments which needed electricity to operate and the duration of using electric equipments whose $\mathrm{R}^{2}$ power was as big as $90 \%$. The duration of using electric equipments had the highest correlation with the value of $62.70 \%$. It is suggested that households should use energy saving equipments such as LED products; the government should consistently promote carbon saving movements; and to future research to calculate carbon footprint by using DNPI carbon calculator, or by using software LEAP.
\end{abstract}

Keywords: Carbon footprint, electricity and LPG consumptions, household

\section{PENDAHULUAN}

Pertumbuhan manusia yang cepat mendorong manusia memanfaatkan alam secara berlebihan. Pemanfaatan tersebut baik sebagai pemukiman maupun usaha untuk mencukupi kebutuhan hidup. Aktivitas-aktivitas manusia telah mengubah lingkungan global dan perubahan lingkungan global ini memiliki bentuk yang bermacam-macam. Perubahan global yang tidak terhitung banyaknya mengakibatkan terjadinya efek rumah kaca. Fenomena efek rumah kaca tersebut berdampak pada pertanian, kenaikan permukaan air laut, dan pengurangan ozon di lapisan stratosfer.

Dalam 50 tahun terakhir manusia telah melakukan lebih banyak aktivitas yang merubah bumi dan ekosistemnya. Sekitar 85\% muka bumi sudah terkontaminasi oleh aktivitas manusia, 35\% daratan bumi telah dimodifikasi untuk tanaman pangan dan budidaya ternak untuk pemenuhan kebutuhan pangan dari 6,8 milyar penduduk bumi. Setiap tahun manusia mengkonsumsi sumber bumi sebesar 1,4 kali lebih banyak dibanding yang mampu diperbaruhi oleh bumi. Aktivitas manusia yang semakin konsumtif menimbulkan perubahan lingkungan yang mengancam keberlangsungan bumi (Arisandi, 2011).

Masalah lingkungan yang sedang terjadi saat ini adalah peningkatan suhu muka bumi. Menurut IPCC (1996), suhu global rata-rata akan meningkat dengan laju $0,3^{\circ} \mathrm{C}$ setiap 10 tahun. Manusia dengan egosentrisnya berusaha memanfaatkan alam semaksimal mungkin dan menjadi pelaku utama dari adanya pemanasan global. Gas rumah kaca hasil aktivitas manusia yang terakumulasi di atmosfer bumi mempengaruhi peningkatan suhu permukaan bumi dari waktu ke waktu.

Saat ini diperkirakan konsentrasi karbondioksida adalah yang paling dominan di atmosfer (Setiawan, at al, 2011). Setiap tahun terjadi peningkatan konsentrasi $\mathrm{CO}_{2}$ di atmosfer yang diikuti dengan peningkatan suhu. Tahun 2001 terjadi peningkatan suhu bumi $0,6^{\circ} \mathrm{C}$ yang merupakan peningkatan suhu tertinggi dalam 100 tahun (Arisandi, 2011). Hal tersebut membuat penilaian aktivitas manusia yang menghasilkan karbondioksida menjadi penting. Salah satu cara untuk mengetahui jumlah nilai emisi yang dihasilkan oleh aktivitas manusia adalah dengan perhitungan jejak karbon.

Nilai emisi karbon yang dihasilkan oleh suatu 
organisasi, peristiwa, produk, dan aktivitas manusia disebut sebagai jejak karbon. Jejak karbon dinyatakan dalam satuan ton karbon atau ton karbondioksida ekuivalen. Jejak karbon adalah suatu ukuran dari aktivitas manusia yang menimbulkan dampak terhadap lingkungan. Semakin banyak aktivitas yang dilakukan oleh manusia, maka semakin tinggi nilai emisi yang dihasilkan. Hal ini menunjukkan terjadinya hubungan antara aktivitas manusia dengan kualitas udara di atmosfer.

Setiap orang dalam aktivitasnya sehari-hari yang menggunakan energi akan menghasilkan emisi karbondioksida $\left(\mathrm{CO}_{2}\right)$, semakin banyak aktivitas manusia maka semakin banyak energi yang digunakan sehingga semakin besar nilai jejak karbonnya (Rahayu, 2011). Dalam IESR. (2011) dinyatakan bahwa saat ini kecenderungan orang untuk hidup senyaman mungkin mendorong munculnya kebiasaan hidup yang berdampak pada lingkungan. Kebiasaan menggunakan kendaraan pribadi terutama mobil dibandingkan dengan kendaraan umum, perjalanan dengan pesawat udara, penggunaan pendingin atau pemanas ruangan, penggunaan perangkat komputer, televisi, radio, dan perangkat hiburan lainnya adalah bentuk kebiasaan hidup yang berkontribusi terhadap banyaknya nilai jejak karbon.

Hampir seluruh kegiatan manusia setiap harinya telah berkontribusi terhadap kenaikan emisi gas rumah kaca di atmosfer. Sebagain besar aktivitas manusia membutuhkan sumber energi. Saat ini aktivitas manusia cenderung berasal dari bahan bakar fosil seperti minyak bumi, gas alam dan batubara. Kebutuhan-kebutuhan tersebut semakin bertambah seiring dengan peningkatan jumlah penduduk, jumlah aktivitas, dan gaya hidup masyarakat. Gaya hidup masyarakat kota yang berinteraksi langsung dengan lingkungan memiliki tingkat kompleksitas yang lebih tinggi apabila dibandingkan dengan masyarakat desa.

Rumah tangga adalah salah satu tempat aktivitas manusia. Di dalam rumah tangga banyak waktu yang dihabiskan oleh penghuninya untuk melakukan berbagai kegiatan. Setiap rumah tangga memiliki keragaman aktivitas dan menghasilkan nilai jejak karbon yang berbeda-beda. Keragaman tersebut disesuaikan dengan jenis aktivitas yang dilakukan oleh anggota rumah tangga yang bersangkutan. Dalam penelitian Wulandari (2013), perumahan kelas atas atau dengan tingkat ekonomi yang lebih tinggi menggunakan energi rumah tangga lebih besar sehingga menghasilkan emisi $\mathrm{CO}_{2}$ yang lebih besar. Penelitian lain dari Wicaksono (2010), disebutkan bahwa faktor yang mempengaruhi emisi $\mathrm{CO}_{2}$ adalah jumlah penggunaan bahan bakar, alatalat listrik yang digunakan di rumah tangga, lama pemakaian alat-alat listrik, daya listrik dan tipe rumah.
Rumah tangga merupakan sektor pengguna energi terbesar ketiga setelah industri dan transportasi. Saat ini permintaan sektor rumah tangga (tanpa biomasa) mencapai 8\% dari total penggunaan energi. Pemanfaatan energi sektor rumah tangga terkait dengan kebutuhan tenaga listrik (untuk penerangan, pengkondisian ruangan, peralatan elektronik lainnya) dan energi panas untuk memasak. Kebutuhan energi panas dipenuhi dengan pembakaran BBM misalnya minyak tanah, LPG, gas bumi (untuk beberapa wilayah kota besar) dan kayu bakar (untuk beberapa wilayah pinggiran kota dan pedesaan). Di beberapa daerah yang belum memiliki akses ke tenaga listrik, kebutuhan akan penerangan dipenuhi dengan memanfaatkan lampu minyak tanah (Kementrian Energi dan Sumber Daya Mineral, 2012).

Saat ini permintaan energi rumah tangga didominasi oleh listrik, disusul oleh LPG dan minyak tanah. Adanya kebijakan subsitusi minyak tanah dengan LPG, permintaan energi rumah tangga masa mendatang diperkirakan akan sangat berbeda dengan kondisi saat ini. Berdasarkan skenario $B A U$, pada periode 2011-2030 permintaan energi sektor rumah tangga akan tumbuh rata-rata $4,3 \%$ per tahun, meningkat dari 12,5 juta ton pada tahun 2011 menjadi 28,0 juta ton pada tahun 2030. Faktor pendorong pertumbuhan permintaan energi sektor rumah tangga adalah pertumbuhan populasi (jumlah rumah tangga) dan daya beli (PDB/kapita). Permintaan energi setiap rumah tangga akan meningkat sejalan dengan pertumbuhan $\mathrm{PDB} / \mathrm{kapita}$ dan akses terhadap energi. Semakin tinggi daya beli suatu keluarga, maka semakin tinggi kebutuhan eneginya. Pada level tertentu, kebutuhan energi setiap rumah tangga akan relatif konstan, tidak lagi dipengaruhi oleh peningkatan daya belinya (Kementrian Energi dan Sumber Daya Mineral, 2012).

Kota Denpasar merupakan salah satu kota besar di Indonesia. Secara astronomis Kota Denpasar terletak pada $08^{\circ} 35^{\prime} 31^{\prime \prime}-08^{\circ} 44^{\prime} 49^{\prime \prime} \mathrm{LS}$ dan $115^{\circ}$ 10' 23" - $115^{\circ} 16^{\prime}$ '27" BT. Jumlah Penduduk Kota Denpasar sebanyak 788.588 jiwa dengan kepadatan penduduk 6.171 per $\mathrm{km}^{2}$ (Badan Pusat Statistik, 2013). Penduduk di Kota Denpasar adalah penduduk yang sangat heterogen dengan berbagai aktivitas dan energi yang dibutuhkan oleh masyarakatnya, dimulai dari usaha, industri, maupun untuk rumah tangga.

Perkembangan Kota Denpasar yang begitu pesat membawa pengaruh terhadap gas rumah kaca. Laporan BLH Kota Denpasar (2014) menyebutkan emisi gas rumah kaca tertinggi terdapat di Kecamatan Denpasar Selatan, hal ini disebabkan oleh padatnya penduduk, adanya PT. Indonesia Power, Pelabuhan Laut dan Industri Pengolahan Ikan. Jumlah emisi yang dihasilkan berupa emisi $\mathrm{CO}_{2}$ 
adalah sebesar $446.618,88 \mathrm{Gg}$, emisi $\mathrm{CH}_{4}$ sebesar $145,87 \mathrm{Gg}$, emisi $\mathrm{N}_{2} \mathrm{O}$ sebesar $18,44 \mathrm{Gg}$, dan $\mathrm{NOx}$ sebesar $111,74 \mathrm{Gg}$.

Emisi rumah tangga dapat dihasilkan dari penggunaan LPG dan energi listrik. Pada kegiatan perumahan menggunakan faktor asumsi yaitu asumsi rumah tangga yang menggunakan LPG 12 kg sebanyak $50 \%$ dari total rumah tangga dengan pemakaian rata-rata 1 tabung/bulan, LPG $3 \mathrm{~kg}$ sebanyak $35 \%$ dari total rumah tangga dengan pemakaian rata-rata 3 tabung/bulan, minyak tanah sebanyak $15 \%$ dari total rumah tangga dengan pemakaian rata-rata sebanyak 5 liter/bulan (Badan Lingkungan Hidup, 2014).

Rumah tangga di Kota Denpasar memiliki tingkat penggunaan daya listrik yang berbeda. Laporan Perusahaan Listrik Negara (2014) menyatakan, rata-rata penggunaan daya listrik rumah tangga di Kota Denpasar dengan jumlah pelanggan 200.713 selama 5 bulan terakhir (JuliNovember 2014) adalah sebesar 53.784.839 kWh. Beban penggunaan energi listrik di Kota Denpasar tertinggi terjadi pada malam hari, yaitu mulai Pukul 18.00 sampai 22.00 WITA. Tingginya penggunaan energi listrik dari setiap rumah tangga mengindikasikan bahwa masyarakat Kota Denpasar sangat konsumtif dalam menggunakan energi.

Keadaan lain seperti tingginya jumlah penduduk di Kota Denpasar dengan beragam aktivitas tentunya akan berpengaruh terhadap nilai jejak karbon yang dihasilkan, namun secara lebih khusus belum diketahui nilai jejak karbon yang dihasilkan dari aktivitas rumah tangga. Demikian juga penelitian yang dilakukan oleh Badan Lingkungan Hidup (2014), belum mengkaji tentang besaran emisi karbon yang dihasilkan oleh rumah tangga. Berangkat dari masalah tersebut, maka penting untuk melakukan penelitian tentang "Jejak Karbon Konsumsi LPG dan Listrik Pada Rumah Tangga Di Kota Denpasar, Bali”.

\section{METODOLOGI}

Rancangan penelitian yang digunakan adalah rancangan deskriptif kuantitatif yang didukung dengan data survei. Waktu penelitian dilakukan selama empat bulan yaitu Januari 2015 sampai April 2015. Jumlah sampel atau responden yang diteliti adalah sebanyak 100 rumah tangga.

Analisis tujuan penelitian yang pertama yaitu nilai jejak karbon dilakukan dengan menggunakan persamaan:

Pey LPG = EF x Fcy LPG x NCV

Emisi $\mathrm{CO}_{2}=\mathrm{EF} \times \mathrm{x}$ konsumsi listrik

Emisi $\mathrm{CO}_{2}^{2}$ Total $=$ Emisi $\mathrm{CO}_{2}$ primer + Emisi $\mathrm{CO}_{2}$ sekunder

Analisis tujuan penelitian kedua yaitu untuk mengetahui faktor yang paling berpengaruh terhadap nilai jejak karbon. Analisis yang dipergunakan adalah analisis regresi linier berganda. Analisis regresi linier berganda dibantu dengan menggunakan program statistik SPSS versi 16 for windows.

\section{HASIL DAN PEMBAHASAN}

Dari 100 rumah tangga yang dijadikan responden, diperoleh bahwa 18 sampel adalah rumah tangga dengan daya listrik $450 \mathrm{kWh}, 26$ sampel dengan daya $900 \mathrm{kWh}$, dan 56 sampel dengan daya e" $1300 \mathrm{kWh}$.

\subsection{Nilai jejak karbon aktivitas rumah tangga di Kota Denpasar}

1) Jejak karbon primer

Jejak karbon primer merupakan ukuran emisi $\mathrm{CO}_{2}$ yang bersifat langsung. Berdasarkan hasil penelitian yang telah dilakukan, nilai jejak primer dapat dilihat pada Tabel 1.

Tabel 1. Hasil Perhitungan Jejak Karbon Primer Aktivitas Rumah Tangga Di Kota Denpasar

\begin{tabular}{|c|c|c|c|c|c|c|c|c|c|}
\hline No & $\begin{array}{l}\text { Daya } \\
\text { Listrik } \\
\text { (kWh) }\end{array}$ & $\begin{array}{l}\text { Jumlah } \\
\text { Sampel } \\
\text { Rumah } \\
\text { Tangga }\end{array}$ & $\begin{array}{c}\text { Rata-rata } \\
\text { Konsumsi LPG } \\
\text { (kg/Bulan) }\end{array}$ & $\begin{array}{c}\text { Faktor } \\
\text { Emisi LPG } \\
\text { (g karbon/ MJ) }\end{array}$ & $\begin{array}{l}\text { Berat Bersih } \\
\text { LPG (MJ/ kg) }\end{array}$ & $\begin{array}{c}\text { Jejak Karbon } \\
\text { Primer } \\
\text { (g karbon/ bulan) }\end{array}$ & $\begin{array}{l}\text { Rata-rata } \\
\text { Jumlah Anggot } \\
\text { Keluarga }\end{array}$ & $\begin{array}{l}\text { Rata-rata } \\
\text { ta Jejak Karbon } \\
\text { Primer tiap Individu } \\
\text { (g karbon/bulan) }\end{array}$ & $(\%)$ \\
\hline 1 & 450 & 18 & 9.83 & 17.20 & 48.852 & 8262.50 & 3.50 & 2360.71 & 28.27 \\
\hline 2 & 900 & 26 & 11.08 & 17.20 & 48.852 & 9307.43 & 3.65 & 2547.30 & 31.84 \\
\hline \multirow[t]{3}{*}{3} & e" 1300 & 56 & 13.88 & 17.20 & 48.852 & 11658.53 & 4.45 & 2622.00 & 39.89 \\
\hline & Jumlah & 100 & 34.79 & & & 29228.46 & 11.60 & & 100.00 \\
\hline & Rata-rata & 11.60 & & & 9742.82 & 3.87 & & & \\
\hline
\end{tabular}

Sumber : Hasil Perhitungan Data Primer, 2015 
Berdasarkan hasil penelitian yang dapat dilihat pada Tabel 1, rata-rata jejak karbon primer setiap rumah tangga adalah 9.742,82 g karbon/bulan. Kontribusi terbesar jejak karbon primer pada rumah tangga lebih banyak disumbangkan oleh rumah tangga dengan daya listrik e" $1300 \mathrm{kWh}$ yaitu 11.658,53 g karbon/bulan/rumah tangga dengan sumbangan sebesar 39,89\%. Hal ini berarti bahwa rumah tangga dengan daya listrik e" $1300 \mathrm{kWh}$ cenderung lebih banyak menggunakan LPG dibandingkan dengan rumah tangga dengan daya listrik lainnya. Kondisi tersebut disebabkan oleh rumah tangga dengan daya listrik e" 1300 kWh memiliki jumlah anggota rumah tangga yang lebih banyak yaitu dengan rata-rata 4,45 orang dan jumlah peralatan rumah tangga yang menggunakan LPG lebih banyak yaitu 1,82 unit.

Sumbangan terbesar kedua jejak karbon konsumsi LPG pada rumah tangga di Kota Denpasar adalah dari rumah tangga dengan daya listrik 900 kWh, yaitu sebesar 9.307,43 g karbon/bulan/rumah tangga atau $31,84 \%$. Rata-rata penggunaan setiap anggota rumah tangga pada rumah tangga adalah sebesar 2.547,30 g karbon/bulan. Rata-rata konsumsi LPG pada rumah tangga dengan daya $900 \mathrm{kWh}$ adalah $11,08 \mathrm{~kg} /$ bulan masih lebih rendah apabila dibandingkan dengan konsumsi LPG pada rumah tangga dengan daya e" 1300 sebesar $13,88 \mathrm{~kg} /$ bulan.

Rumah tangga dengan daya listrik $450 \mathrm{kWh}$ adalah rumah tangga yang paling rendah dalam menghasilkan jejak karbon primer. Dilihat dari jumlah anggota rumah tangganya, rumah tangga dengan daya listrik $450 \mathrm{kWh}$ memiliki rata-rata anggota rumah tangga sebanyak 3,5 orang dan emisi yang dihasilkan yaitu sebesar 2.360,71 g karbon/ bulan. Jejak karbon primer rumah tangga yang dihasilkan adalah 8.262,50 g karbon/bulan/rumah tangga atau memberikan sumbangan sebesar $28,27 \%$ dari total jejak karbon primer. Kondisi tersebut disebabkan oleh rata-rata konsumsi LPG yaitu $9,83 \mathrm{~kg}$ / bulan dengan rata-rata pemakaian per hari adalah 1,36 jam/ hari serta jumlah anggota rumah tangga yang paling sedikit diantara rumah tangga dengan daya $900 \mathrm{kWh}$ dan e" $1300 \mathrm{kWh}$.

\section{2) Jejak karbon primer}

Jejak karbon sekunder merupakan emisi karbondioksida yang bersifat tidak langsung. Jejak karbon sekunder dihasilkan dari peralatan-peralatan elektronik rumah tangga dimana peralatan elektronik ini dapat difungsikan dengan menggunakan daya listrik. Jejak karbon sekunder dari aktivitas rumah tangga dapat dilihat pada Tabel 2.

Berdasarkan Tabel 2, rata-rata jejak karbon sekunder setiap rumah tangga adalah 128.294,20 g karbon/bulan. Jejak karbon sekunder tertinggi terdapat pada rumah tangga dengan daya listrik e" $1300 \mathrm{kWh}$, yaitu sebesar 41,98\% atau sebesar 161.579,04 g karbon/bulan/rumah tangga. Besarnya sumbangan jejak karbon sekunder yang diberikan tersebut disebabkan oleh banyaknya alat-alat elektronik yang dioperasikan. Diperkiran alat-alat yang memberikan sumbangan besar pada rumah tangga e" $1300 \mathrm{kWh}$ adalah kulkas, jumlah televisi lebih dari satu dengan penggunaan yang intensitasnya tinggi, serta pendingin ruangan (AC) yang dapat dijumpai pada setiap rumah. Faktor lain yang menyebabkan tingginya jejak karbon sekunder dari rumah tangga dengan daya listik e" $1300 \mathrm{kWh}$ adalah jumlah anggota rumah tangga yaitu sebanyak 4,45 orang. Rata-rata setiap orang dalam rumah tangga tersebut menghasilkan karbon sebesar 36.339,06 g karbon/bulan.

Rumah tangga dengan daya listrik $450 \mathrm{kWh}$ adalah rumah tangga yang paling rendah menghasilkan jejak karbon sekunder. Jejak karbon sekunder yang dihasilkan yaitu 98.350,33 g karbon/ bulan/rumah tangga atau sumbangan sebesar 25,55\%. Hal tersebut disebabkan oleh peralatan elektronik yang terdapat pada rumah tangga dengan daya $450 \mathrm{kWh}$ hanya sebatas peralatan yang sifatnya sangat penting dan jumlah yang sedikit. Peralatan elektronik yang terdapat pada rumah tangga dengan daya listrik $450 \mathrm{kWh}$ seperti 1 buah televisi, 1 buah alat memasak nasi, 6 buah lampu yang digunakan seperlunya, 1 buah kipas, dan 1 kulkas berukuran kecil. Hal lain juga disebabkan oleh tipe rumah yang relatif kecil sehingga tidak memungkinkan untuk mengisi dengan banyak peralatan elektronik.

Tabel 2. Hasil Perhitungan Jejak Karbon Sekunder Aktivitas Rumah Tangga Di Kota Denpasar

\begin{tabular}{|c|c|c|c|c|c|c|c|c|}
\hline No. & $\begin{array}{l}\text { Daya } \\
\text { Listrik } \\
\text { (kWh) }\end{array}$ & $\begin{array}{c}\text { Jumlah } \\
\text { Sampel } \\
\text { Rumah Tangga }\end{array}$ & $\begin{array}{l}\text { Rata-rata } \\
\text { Konsumsi } \\
\text { Listrik } \\
\text { (kWh/ bulan) }\end{array}$ & $\begin{array}{c}\text { Faktor } \\
\text { Emisi } \\
\text { Listrik } \\
\text { (g karbon/ kWh) }\end{array}$ & $\begin{array}{c}\text { Jejak } \\
\text { Karbon } \\
\text { Sekunder } \\
\text { (g karbon/ bulan) }\end{array}$ & $\begin{array}{l}\text { Rata-rata } \\
\text { Jumlah } \\
\text { Anggota } \\
\text { Keluarga }\end{array}$ & $\begin{array}{c}\text { Rata-rata } \\
\text { Jejak Karbon Sekunder } \\
\text { tiap Individu } \\
\text { (g karbon/bulan) }\end{array}$ & $(\%)$ \\
\hline 1 & 450 & 18 & 167.83 & 586 & 98350.33 & 3.50 & 28100.10 & 25.55 \\
\hline 2 & 900 & 26 & 213.23 & 586 & 124953.23 & 3.65 & 34197.73 & 32.47 \\
\hline \multirow[t]{3}{*}{3} & e" 1300 & 56 & 275.73 & 586 & 161579.04 & 4.45 & 36339.06 & 41.98 \\
\hline & Jumlah & 100 & 656.80 & & 384882.60 & 11.60 & & 100.00 \\
\hline & Rata-rata & 218.93 & & 128294.20 & 3.87 & & & \\
\hline
\end{tabular}

Sumber : Hasil Perhitungan Data Primer, 2015 
Tabel 3. Hasil Perhitungan Jejak Karbon Total Aktivitas Rumah Tangga Di Kota Denpasar

\begin{tabular}{|c|c|c|c|c|c|c|c|c|}
\hline No. & $\begin{array}{l}\text { Daya } \\
\text { Listrik } \\
\text { (kWh) }\end{array}$ & $\begin{array}{c}\text { Jumlah } \\
\text { Sampel } \\
\text { Rumah Tangga }\end{array}$ & $\begin{array}{l}\text { Rata-rata } \\
\text { Konsumsi } \\
\text { Listrik } \\
\text { (kWh/ bulan) }\end{array}$ & $\begin{array}{c}\text { Faktor } \\
\text { Emisi } \\
\text { Listrik } \\
\text { (g karbon/ kWh) }\end{array}$ & $\begin{array}{c}\text { Jejak } \\
\text { Karbon } \\
\text { Sekunder } \\
\text { (g karbon/ bulan) }\end{array}$ & $\begin{array}{l}\text { Rata-rata } \\
\text { Jumlah } \\
\text { Anggota } \\
\text { Keluarga }\end{array}$ & $\begin{array}{c}\text { Rata-rata } \\
\text { Jejak Karbon Sekunder } \\
\text { tiap Individu } \\
\text { (g karbon/bulan) }\end{array}$ & $(\%)$ \\
\hline 1 & 450 & 18 & 8262.50 & 98350.33 & 106612.83 & 3.50 & 30460.81 & 25.74 \\
\hline 2 & 900 & 26 & 9307.43 & 124953.23 & 134260.66 & 3.65 & 36745.02 & 32.42 \\
\hline \multirow[t]{3}{*}{3} & e" 1300 & 56 & 11658.53 & 161579.04 & 173237.57 & 4.45 & 38961.06 & 41.83 \\
\hline & Jumlah & 100 & 29228.46 & 384882.60 & 414111.06 & 11.60 & & 100.00 \\
\hline & Rata-rata & 9742.82 & 128294.20 & 138037.02 & 3.87 & & & \\
\hline
\end{tabular}

Sumber : Hasil Perhitungan Data Primer, 2015

3) Jejak karbon total

Jejak karbon total merupakan hasil penjumlahan dari jejak karbon primer dengan jejak karbon sekunder. Hasil penelitian jejak karbon total rumah tangga di Kota Denpasar dapat dilihat pada Tabel 3.

Berdasarkan Tabel 3, rata-rata jejak karbon yang dihasilkan oleh setiap rumah tangga adalah 138.037,02 g karbon/bulan. Jejak karbon total konsumsi LPG dan listrik pada rumah tangga dengan daya listrik e" $1300 \mathrm{kWh}$ adalah yang paling tinggi. Besaran sumbangan jejak karbon total dari rumah tangga dengan daya listrik e" 1300 adalah $41,83 \%$. Nilai jejak karbon total paling rendah terdapat pada aktivitas rumah tangga dengan daya listrik $450 \mathrm{kWh}$ atau sebesar $25,74 \%$ dengan jejak karbon total sebesar 106.612,83 g karbon/bulan/ rumah tangga. Kehidupan sehari-hari dari rumah tangga dengan daya listrik $450 \mathrm{kWh}$ lebih sedikit yang menggunakan alat-alat dengan LPG dan daya listrik. Berdasarkan hasil observasi memang menunjukkan bahwa keseharian rumah tangga dengan daya listrik $450 \mathrm{kWh}$ banyak menghabiskan waktunya untuk beraktivitas di luar ruangan dan hanya berada di rumah pada malam hari.

Nilai jejak karbon total dari rumah tangga dengan daya listrik e" $1300 \mathrm{kWh}$ adalah $173.237,57$ $\mathrm{g}$ karbon/bulan/rumah tangga. Apabila dilihat dari gaya hidup sehari-hari, aktivitas rumah tangga dengan daya listrik e" $1300 \mathrm{kWh}$ termasuk rumah tangga yang konsumtif dengan banyak peralatan yang menggunakan LPG dan daya listrik. Terkait dengan penggunaan listrik, rumah tangga ini cenderung lebih banyak menggunakan peralatan listrik. Alat-alat yang digunakan lebih banyak pada sarana hiburan seperti televisi, tape, pendingin ruangan (AC), dan kulkas. Hal lain yang menyebabkan perbedaan jumlah konsumsi LPG dan listrik adalah jumlah anggota keluarga. Perbandingan dari jumlah anggota rumah tangga pada tiap daya listrik adalah 3,50 orang pada rumah tangga dengan daya listrik $450 \mathrm{kWh}, 3,65$ orang untuk rumah tangga dengan daya listrik $900 \mathrm{kWh}$, dan 4,45 orang untuk rumah tangga dengan daya listrik e" $1300 \mathrm{kWh}$. Faktor tersebut menjadi indikator yang memberikan pengaruh terhadap besaran jejak karbon yang dihasilkan.

Berdasarkan rata-rata jejak karbon total yang telah diperoleh, maka jejak karbon total dari konsumsi LPG dan listrik di Kota Denpasar dengan jumlah rumah tangga sebanyak 15.908 (Badan Pusat Statistik, 2013) adalah 2.195.892.938 g karbon/bulan atau setara dengan $2.195,89$ ton $\mathrm{CO}_{2} \mathrm{e} / \mathrm{bulan}$.

\subsection{Faktor-faktor yang paling mempengaruhi nilai jejak karbon aktivitas rumah tangga Di Kota Denpasar}

Berdasarkan hasil penelitian, dapat diketahui bahwa nilai $\mathrm{F}_{\text {hitung }}$ sebesar 168,916. Perhitungan dengan menggunakan tingkat keyakinan $90 \%$, a = $10 \%$, df1 (jumlah variabel-1) $=4$, dan df2 $(\mathrm{n}-\mathrm{k}-1)$ atau 100-5-1 = 94, hasil diperoleh untuk $\mathrm{F}_{\text {tabel }}$ adalah 3,525 . Hal ini menunjukkan bahwa $\mathrm{F}_{\text {hitung }}>\mathrm{F}_{\text {tabel }}$ $(168,916>3,525)$, sehingga artinya terdapat pengaruh secara signifikan antara variabel bebas dengan variabel terikat secara bersama-sama. Merujuk pada hipotesis pada rumusan masalah kedua, maka terdapat hubungan positif antara faktor-faktor yang mempengaruhi nilai jejak karbon di Kota Denpasar. Faktor-faktor yang mempengaruhi nilai jejak karbon (Y) adalah jumlah anggota rumah tangga $\left(\mathrm{X}_{1}\right)$, jumlah alat rumah tangga yang menggunakan LPG $\left(\mathrm{X}_{2}\right)$, lama penggunaan alat rumah tangga yang menggunakan LPG $\left(\mathrm{X}_{3}\right)$, jumlah alat rumah tangga yang menggunakan daya listrik $\left(\mathrm{X}_{4}\right)$, dan lama penggunaan alat rumah tangga yang menggunakan daya listrik $\left(\mathrm{X}_{5}\right)$. Hasil penelitian tersebut didukung oleh Wicaksono (2010), yang menyebutkan bahwa faktor yang mempengaruhi emisi $\mathrm{CO}_{2}$ adalah jumlah penggunaan bahan bakar, alat-alat listrik yang digunakan di rumah tangga, waktu pemakaian alatalat listrik, daya listrik, dan tipe rumah. Hal yang sama diungkapkan oleh Astari (2012), yang menyatakan bahwa faktor-faktor yang mempengaruhi nilai emisi yang dihasilkan dari suatu rumah tangga yaitu tipe rumah, daya listrik, dan jumlah penghasilan. Penelitian lain dari Li \& Wang (2010), juga disebutkan bahwa pendidikan kepala 
rumah tangga, usia kepala rumah tangga, ukuran rumah tangga, dan faktor-faktor geografis mempengaruhi nilai karbon rumah tangga. Hasil penelitian lain dari Grunewald et al. (2012), menyatakan bahwa pendapatan, usia, jenis kelamin, dan pendidikan kepala keluarga mempengaruhijejak karbon yang dihasilkan rumah tangga. Penelitian Jaiswal \& Shah (2013), menyebutkan bahwa faktor pendapatan, banyak anggota keluarga, status pekerjaan, dan jenis keluarga mempengaruhi jejak karbon yang dihasilkan. Pada penelitian tersebut disebutkan faktor yang paling berpengaruh adalah banyak anggota keluarga.

Melalui analisis korelasi dicari pengaruh variabel bebas terhadap variabel terikat. Hasil perhitungan menunjukkan bahwa koefisien korelasi antara variabel bebas dan terikat adalah sebesar 0,949 yang berarti bahwa terjadi hubungan yang sangat kuat antara variabel terikat (Y) dengan variabel bebas variabel $(\mathrm{X})$ yaitu jumlah anggota rumah tangga $\left(\mathrm{X}_{1}\right)$, jumlah alat rumah tangga yang menggunakan LPG $\left(\mathrm{X}_{2}\right)$, lama penggunaan alat rumah tangga yang menggunakan LPG $\left(\mathrm{X}_{3}\right)$, jumlah alat rumah tangga yang menggunakan daya listrik $\left(\mathrm{X}_{4}\right)$, dan lama penggunaan alat rumah tangga yang menggunakan daya listrik $\left(\mathrm{X}_{5}\right)$. Nilai $\mathrm{R}^{2}$ (R Square) sebesar 0,900 atau $90 \%$. Hal ini menunjukkan bahwa sumbangan pengaruh variabel bebas $\left(\mathrm{X}_{1}, \mathrm{X}_{2}, \mathrm{X}_{3}, \mathrm{X}_{4}\right.$, dan $\left.\mathrm{X}_{5}\right)$ terhadap variabel terikat (jejak karbon total (Y)) sebesar $90 \%$. Pengaruh masing-masing variabel bebas $(\mathrm{X})$ terhadap variabel terikat $(\mathrm{Y})$ menunjukkan bahwa variabel lama penggunaan alat rumah tangga yang menggunakan daya listrik $\left(\mathrm{X}_{5}\right)$ memiliki pengaruh yang paling besar diantara variabel bebas yang lainnya yaitu sebesar 0,627 atau $62,70 \%$

\section{SIMPULAN DAN SARAN}

\subsection{Simpulan}

Berdasarkan hasil penelitian dan pembahasan yang telah diuraikan pada bagian sebelumnya, maka kesimpulan dari penelitian ini adalah.

1. Rata-rata jejak karbon total konsumsi LPG dan listrik yang dihasilkan oleh setiap rumah tangga di Kota Denpasar adalah 138.037,02 g karbon/ bulan/rumah tangga yang masing-masing disumbangkan oleh konsumsi LPG sebesar 9.742,82 g karbon/bulan/rumah tangga dan konsumsi listrik sebesar 128.294,20 g karbon/ bulan/rumah tangga.

2. Faktor yang paling mempengaruhi besaran nilai jejak karbon konsumsi LPG dan listrik pada rumah tangga di Kota Denpasar adalah lama penggunaan alat rumah tangga yang menggunakan daya listrik dengan kontribusi sebesar $62,70 \%$.

\subsection{Saran}

Berdasarkan pada hasil penelitian, pembahasan, dan simpulan, maka saran yang dapat diajukan adalah sebagai berikut.

1. Bagi para anggota rumah tangga sebaiknya menggunakan alat-alat yang hemat energi seperti alat-alat LED yang dapat mengurangi jejak karbon sekunder.

2. Bagi pihak pemerintah senantiasa untuk mempromosikan gerakan hemat karbon dan mempercepat pembangunan millennium. Bagi pihak swasta sebagai produsen barang-barang rumah tangga sebaiknya membuat produk yang hemat energi dan berpedoman pada konsep lingkungan.

3. Bagi mahasiswa dan penelitian lanjutan yang berhubungan dengan jejak karbon sebaiknya perlu menghitung jejak karbon dengan kalkulator karbon DNPI atau dengan software LEAP.

\section{DAFTAR PUSTAKA}

Arisandi, P. (2011). Ecoton : Lembaga Kajian Ekologi dan Konservasi Lahan Basah. Haettu 26. May 2014 osoitteesta http://www.ecoton.or.id/ tulisanlengkap.php?id=2209

Astari, R. G. (2012). Studi Jejak Karbon Dari Aktivitas Permukiman Di Kecamatan Pademangan Kotamadya Jakarta Utara. Depok: Fakultas Teknik, Program Studi Teknik Lingkungan, Universitas Indonesia.

Badan Lingkungan Hidup. (2014). Inventarisasi Gas Rumah Kaca Di Kota Denpasar Tahun 2014. Denpasar: Badan Lingkungan Hidup.

Badan Pusat Statistik. (2013). Denpasar Dalam Angka 2013. Denpasar: BPS.

Grunewald, N. H. (2012). The Carbon Footprint of Indian Households. Paper Prepared for the 32nd General Conference of The International Association for Research in Income and Wealth, (s. 6A). Boston, USA.

IESR. (2011). Factsheet Jejak Karbon (Carbon Footprint). Haettu 30. Maret 2014 osoitteesta http://www.iesr-indonesia.org/wp-content/ uploads/factsheet_carbon.pdf

IPCC. (1996). The Emission Factors For Natural Gas Are From IPCC Tier 1 Default Emission Factors.

Jaiswal, N. dan Shah, K. (2013). Assessment of Carbon Footprints of Rural Households of Vadodara District, Gujarat, India. Indian Journal of Applied Research Volume3 ISSN2249-555X, 243-245. 
Kementrian Energi dan Sumber Daya Mineral. (2012). Kajian Indonesia Energi Outlook.

Li, J. dan Wang, Y. (2010). Income, lifestyle and household carbon footprints (carbon-income relationship), a micro-level analysis on China's urban and rural household surveys. Environmental Economics, Volume 1, Issue 2, 44-71.

Perusahaan Listrik Negara. (2014). Laporan Penggunaan Daya Listrik. Denpasar: PLN Area Bali Selatan.

Rahayu, M. (2011). Hutang Karbon dan Isu Pemanasan Global. Haettu 20. Mei 2014 osoitteesta http://www.kabarindonesia.com/ berita.php?pil=4\&jd=Hutang+Karbon+dan+Isu+ Pemanasan+Global\&dn=20110613051316.
Setiawan, R. Y., Boedisantoso, R., dan Razif, M. (2011). Kajian Carbon Footprint Dari Kegiatan Industri Di Kota Surabaya. Seminar Nasional Teknik Lingkungan VII. ISBN 978-602-95595$2-1$.

Wicaksono, A. M. (2010). Studi Carbon Footprint (CO2) Dari Kegiatan Permukiman Di Surabaya Bagian Barat.

Wulandari, M. T. (2013). Kajian Emisi CO2 Berdasarkan Penggunaan Energi Rumah Tangga Sebagai Penyebab Pemanasan Global. Seminar Nasional Pengelolaan Sumberdaya Alam dan Lingkungan (ss. 434-440). ISBN 978602-17001-1-2. 